\title{
UV Absorbing Property of Ageratum conyzoides Linn Leaves: Effects of Temperature and Time on Extraction Process
}

\author{
Tanaya Ghosh ${ }^{1}$, Prasenjit Mitra ${ }^{2}$ and Prasanta Kumar Mitra ${ }^{1 *}$ \\ ${ }^{1}$ Department of Medical Biotechnology, Sikkim Manipal University, Sikkim Manipal \\ Institute of Medical Sciences, Gangtok, Sikkim, India \\ ${ }^{2}$ Department of Biochemistry, All India Institute of Medical Sciences (AIIMS), \\ Jodhpur, Rajasthan, India \\ *Corresponding Author: Prasanta Kumar Mitra, Professor and Head, Department \\ of Medical Biotechnology, Sikkim Manipal University, Sikkim Manipal Institute of \\ Medical Sciences, Gangtok, Sikkim, India.
}

Received: February 19, 2020

Published: February 27, 2020

(C) All rights are reserved by Prasanta Kumar Mitra., et al.

\section{Abstract}

Recently we have noted anti solar activity of ethanol extract of Ageratum conyzoides Linn (A. conyzoides L.) leaves. We did extraction of the plant leaves to establish this pharmacological activity. As it is known that pharmacological activity of a plant depends on temperature and time of extraction process, aim of the present work was to see effects of temperature and time of the extraction process on anti solar activity of ethanol extract of $A$. conyzoides L. leaves. A. conyzoides L. leaves were collected and identified by the taxonomist. Ethanol extracts of the leaves were prepared separately at temperatures $20,37,55,70$ degree centigrade for 10,15 , 30, 50 minutes. Anti solar activity of different extracts was checked by a spectrophotometer taking absorption in UV region (200 - 400 $\mathrm{nm}$ ) at $10 \mathrm{~nm}$ intervals. Results showed that ethanol extract of $A$. conyzoides L. leaves at 370C for 15 minutes showed maximum anti solar activity. These conditions may be maintained for isolation work of the anti solar compound from $A$. conyzoides L. leaves. Keywords: Ageratum conyzoides Linn. Leaves; Solvent Extractions; Temperature; Time; Anti Solar Activity
\end{abstract}

\section{Introduction}

Extraction process is carried out to demonstrate pharmacological activity of plants and/or to isolate active ingredients from plants and other sources. There are several techniques of extraction process. These include hot continuous extraction (Soxhlet), digestion, decoction, infusion, counter current extraction, maceration, percolation, sonication, microwave-assisted extraction etc. In all these techniques temperature has a considerable role on the rate of extraction. Hamzah., et al. studied effect of extraction temperature on the extraction of phenolic compounds from Orthosiphon stamineus leaves. It was found out that a temperature of $160^{\circ} \mathrm{C}$ is required for optimum extraction of phenolic compounds from 0 . stamineus leaves [1]. While studying effect of temperature on extraction process of total phenolic content of henna (Lawsonia inermis) stems Tan., et al. observed that $55^{\circ} \mathrm{C}$ temperature was most suitable for extraction process to collect maximum amount of phenolic compounds from henna [2]. Wingard and Phillips studied effect of temperature on the rate of extraction of crude oils from vegetable oil seeds with solvents and noted that rate of extraction varied with temperature [3].

Sulaiman., et al. studied effect of time on extraction of phenolic compounds vis-a-vis anti-radical activity of Clinacanthus nutans Lindau leaves. Authors observed that 120 min extraction is needed to get maximum phenolic compounds thereby maximum anti-radical activity of $C$. nutans Lindau leaves [4]. Effect of duration time of maceration on nitrate content of Vernonia cinerea (L.) was studied by Chaowalit and Chitradee. Authors showed that sixty min macer- ation was needed to get maximum nitrate from V. cinerea [5]. Mahmoud., et al. showed that forty five min extraction was needed to get maximum antioxidant activity of one species of Lavandula [6].

A. conyzoides L. (family, Asteraceae) is a medicinal plant. The plant is native to tropical America, especially Brazil and considered an invasive weed in many other regions. A. conyzoides L. is found throughout India in garden areas, waste places and in the middle hill up to the height of $6000 \mathrm{ft}$ [7]. The plant is known by different names - goat weed (English), jangli pudina (Hindi), helukasa (Kanada), kattappa (Malayalam), vosadi (Marathi), visamustih (Sanskrit), pumpul (Tamil), pokapanthi (Telugu) etc. Throughout year the plant gives flower, purple white flower appears [8].

A. conyzoides L. is described in Ayurveda, Charaka Samhita and Sushruta Samhita as emetic, purgative, febrifuge, antispasmodic and antiasthmatic. In different folkloric system of medicine the plant is used to treat pneumonia, wounds, chronic ulcer, boils, frontal headache, malaria, stomach ailments, rheumatism, colic, sore throat, skin disorders, sleeping sickness etc. [9]. In traditional medicine leaves and root of $A$. conyzoides L. are widely utilized - root juice as antibiotic, leaf juice as eye lotion [10].

Many phytochemicals are identified and characterized in different parts of $A$. conyzoides L. Few of them are, 6-(1-ethoxyethyl)7-methoxy-2,2-dimethylchromene, $\quad 5,6,7,8,3$ ',4',5'-heptamethoxyflavone (5'-methoxynobiletin), 5,6,7,3',4'5'-hexamethoxy flavone, 6-(1-hydroxy ethyl)-7-methoxy-2,2-dimethylchromene, 4'-hydroxy-5,6,7,8,3'-pentamethoxyflavone, coumalic acid, pro- 
tocatechuic acid, 4'-hydroxy-5,6,7,8,3',5'-hexamethoxyflavone, 5,6,7,8,3'-pentamethoxy-4', $\quad$ 5,6,7,5'-tetramethoxy-3',4'-methylenedioxyflavon, etc. [11].

A. conyzoides $\mathrm{L}$. possesses a wide range of pharmacological activities. These include, antioxidant, antimicrobial, anti-inflammatory, antidiabetic, antitumor, anthelmintic, antiulcerogenic, hepatoprotective, anticonvulsant, radioprotective, gastroprotective, antiprotozoal, analgesic, cytotoxic allelopathic, insecticidal, haematopoietic, wound healing, anti-cataleptic etc. [12].

Recently, we have noted anti solar activity of ethanol extract of A. conyzoides L leaves. Paper is under communication. Aim of the present work was to see effects of temperature and time on the extraction process to get maximum anti solar activity of $A$. conyzoides L leaves.

\section{Methodology}

Plant material

A. conyzoides $\mathrm{L}$. leaves were collected from the medicinal plants garden of the University of North Bengal, Siliguri (26041'30.9984" N, 88027'4.5756" E, elevation, 410 ft), Dist. Darjeeling, West Bengal, India sometimes in the month of April, 2019 in morning hours (9 - $10 \mathrm{AM}$ ). Leaves were authenticated by the taxonomist of the department of Botany of the University of North Bengal, Siliguri. A voucher specimen (No. SM-MB-08) was kept in the department of Medical Biotechnology, Sikkim Manipal Institute of Medical Sciences of Sikkim Manipal University, Gangtok, Sikkim, India for future references.

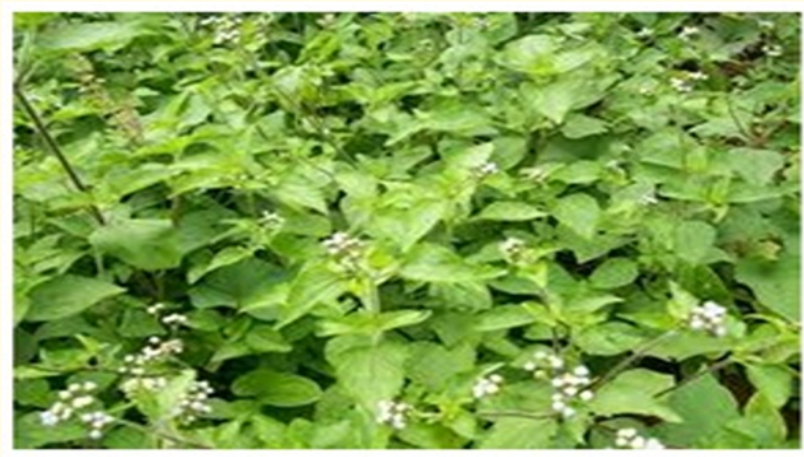

A. conyzoides $\mathrm{L}$.

Figure a

\section{Test drug}

Leaves of $A$. conyzoides L. were washed thoroughly under tap followed by distilled water. Leaves were then shed dried and powered. The powder, used as test drug, was stored desiccated at $40 \mathrm{C}$ until further use.

\section{Solvent extraction}

Test drug (50g) was extracted with $500 \mathrm{ml}$ of ethanol. Ethanol was chosen as solvent because in our earlier experiments we found that ethanol extract of $A$. conyzoides $\mathrm{L}$. leaves had maximum anti solar activity.

Effect of temperature on extraction process

In separate experiments extraction processes were carried out at $20,37,55,70$ degree centigrade.

Effect of time on extraction process

Extraction processes were done separately for 10, 15, 30, 50 minutes.

The extract was filtered and the filtrate evaporated to dryness in vacuo with rotary evaporator. This was applied separately for all extracts. Brown masses obtained.

\section{Anti solar activity}

$10 \mathrm{mg}$ of this mass was dissolved in $100 \mathrm{ml}$ distilled water. The solution was processed in a spectrophotometer for UV ray absorption at the range of $200-400 \mathrm{~nm}$ at $10 \mathrm{~nm}$ intervals

\section{Chemicals}

Chemicals required for the study were purchased from Loba Chem. Lab, Himedia Lab, India and from Merck, Germany

\section{Statistical analysis}

All experiments were conducted thrice. Data were analysed statistically by SPSS 20 . The statistical significance between UV absorption spectra of different extracts was evaluated with Duncan's multiple range test (DMRT). $5 \%$ were considered to be statistically significant [13].

\section{Results and Discussion}

Effect of temperature on extraction process for determination of anti solar activity of $A$. conyzoides $\mathrm{L}$. leaves is shown in table 1. UV ray absorptions of ethanol extract of $A$. conyzoides L. leaves at $20^{\circ} \mathrm{C}$ for $15 \mathrm{~min}$ (as in earlier studies we kept 15 minutes as extraction time) were $0.95,0.71,0.63,0.55,0.46$ at $200 \mathrm{~nm}, 250 \mathrm{~nm}, 300$ $\mathrm{nm}, 350 \mathrm{~nm}$ and $400 \mathrm{~nm}$ respectively. For temperature $370 \mathrm{C}$ under same condition values came $1.3(200 \mathrm{~nm}), 0.98(250 \mathrm{~nm}), 0.88$ $(300 \mathrm{~nm}), 0.72(350 \mathrm{~nm})$ and $0.60(400 \mathrm{~nm})$. UV ray absorptions of ethanol extract of $A$. conyzoides L. leaves at $550 \mathrm{C}$ for $15 \mathrm{~min}$ were $1.29,0.99,0.86,0.73,0.58$ at $200 \mathrm{~nm}, 250 \mathrm{~nm}, 300 \mathrm{~nm}, 350 \mathrm{~nm}$ and $400 \mathrm{~nm}$ respectively. For temperature $700 \mathrm{C}$ under same conditions values came $1.31(200 \mathrm{~nm}), 0.95(250 \mathrm{~nm}), 0.82$ (300 nm), 0.74 $(350 \mathrm{~nm})$ and $0.61(400 \mathrm{~nm})$.

Effect of time on extraction process for determination of anti solar activity of A. conyzoides L. leaves is shown in table 2 . UV ray absorptions of 10 minutes at $37^{\circ} \mathrm{C}$ (as in this experiment $37^{\circ} \mathrm{C}$ was found optimum) ethanol extract of A. conyzoides $L$ leaves at 200 $\mathrm{nm}, 250 \mathrm{~nm}, 300 \mathrm{~nm}, 350 \mathrm{~nm}$ and $400 \mathrm{~nm}$ were 1.0, 0.81, 0.76, 0.70, 0.52 respectively. For $15 \mathrm{~min}$ extraction time under the same condition values came $1.4(200 \mathrm{~nm}), 0.95(250 \mathrm{~nm}), 0.86(300 \mathrm{~nm}), 0.75$ 


\begin{tabular}{|c|c|c|}
\hline Solvent & $\begin{array}{c}\text { Temperature } \\
\text { (Degree centigrade) } \\
\text { Time: } 15 \text { minutes (Fixed) }\end{array}$ & $\begin{array}{c}\text { Anti solar activity } \\
\text { (absorptions at } 200 / 250 / \\
300 / 350 / 400 \mathrm{~nm})\end{array}$ \\
\hline \multirow[t]{4}{*}{ Ethanol } & 0 & $0.95 / 0.71 / 0.63 / 0.55 / 0.46$ \\
\hline & 37 & $1.3 / 0.98 / 0.88 / 0.72 / 0.60$ \\
\hline & 55 & $1.29 / 0.99 / 0.86 / 0.73 / 0.58$ \\
\hline & 70 & $1.31 / 0.95 / 0.82 / 0.74 / 0.61$ \\
\hline
\end{tabular}

Table 1: Anti solar activity of ethanol extract of A. conyzoides L. leaves : Effect of temperature on extraction process.

$(350 \mathrm{~nm})$ and $0.64(400 \mathrm{~nm})$. UV ray absorptions of 30 minutes at $370 \mathrm{C}$ ethanol extract of $A$. conyzoides L. leaves at $200 \mathrm{~nm}, 250 \mathrm{~nm}$, $300 \mathrm{~nm}, 350 \mathrm{~nm}$ and $400 \mathrm{~nm}$ were 1.4, 0.92, $0.850 .76,0.63$ and for $50 \mathrm{~min}$ at $370 \mathrm{C}$ extraction time the values came $1.4(200 \mathrm{~nm}), 0.95$ $(250 \mathrm{~nm}), 0.87(300 \mathrm{~nm}), 0.75(350 \mathrm{~nm})$ and $0.65(400 \mathrm{~nm})$.

\begin{tabular}{|c|c|c|}
\hline Solvent & $\begin{array}{c}\text { Time (minutes)Tem- } \\
\text { perature: } \mathbf{3 7}^{\mathbf{0}} \mathbf{C} \text { (Fixed) }\end{array}$ & $\begin{array}{c}\text { Anti solar activity (absorp- } \\
\text { tions at 200/ 250/ 300/ 350/ } \\
\mathbf{4 0 0} \mathbf{~ n m} \text { ) }\end{array}$ \\
\hline Ethanol & 10 & $1.0 / 0.81 / 0.76 / 0.70 / 0.52$ \\
& 15 & $1.4 / 0.950 .86 / 0.75 / 0.64$ \\
& 30 & $1.4 / 0.92 / 0.85 / 0.76 / 0.63$ \\
& 50 & $1.4 / 0.95 / 0.87 / 0.75 / 0.65$ \\
\hline
\end{tabular}

Table 2: Anti solar activity of ethanol extract of $A$. conyzoides $\mathrm{L}$. leaves : Effect of time on extraction process.

Effect of temperature of extraction process on anti solar activity of ethanol extract of $A$. conyzoides L. leaves is shown in figure 1. A. conyzoides $\mathrm{L}$. leaves when extracted with ethanol at $20^{\circ} \mathrm{C}, 37^{\circ} \mathrm{C}$, $55^{\circ} \mathrm{C}$ and $70^{\circ} \mathrm{C}$ separately absorbed UV radiations at $200 \mathrm{~nm}, 250$ $\mathrm{nm}, 300 \mathrm{~nm}, 350 \mathrm{~nm}$ and $400 \mathrm{~nm}$ wave lengths. Maximum absorption for all extracts was found at $200 \mathrm{~nm}$. Ethanol extract of $A$. conyzoides $\mathrm{L}$. leaves done at $37^{\circ} \mathrm{C}$ had more UV ray absorption capacity than that of $20^{\circ} \mathrm{C}$ extract but the results were not statistically significant. Ethanol extracts of $A$. conyzoides $\mathrm{L}$. leaves done at $55^{\circ} \mathrm{C}$ and $70^{\circ} \mathrm{C}$ had more or less same UV ray absorption capacity when compared to that of ethanol extract done at $40^{\circ} \mathrm{C}$ (Figure 2).

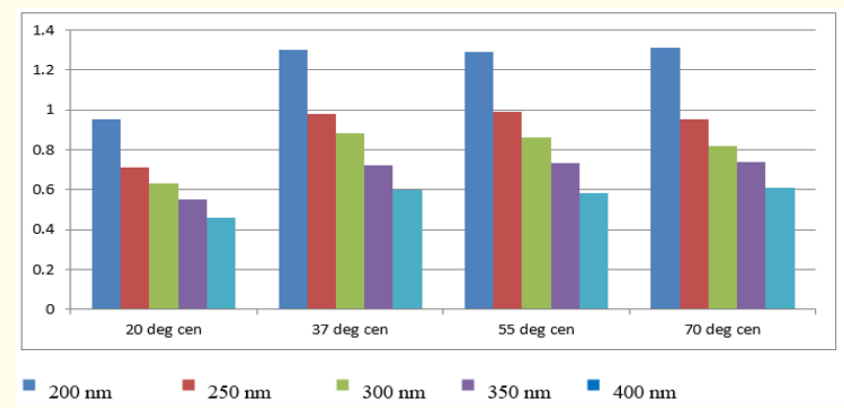

Figure 1: Anti solar activity of ethanol extract of A. conyzoides L. leaves: Effect temperature on extraction process.

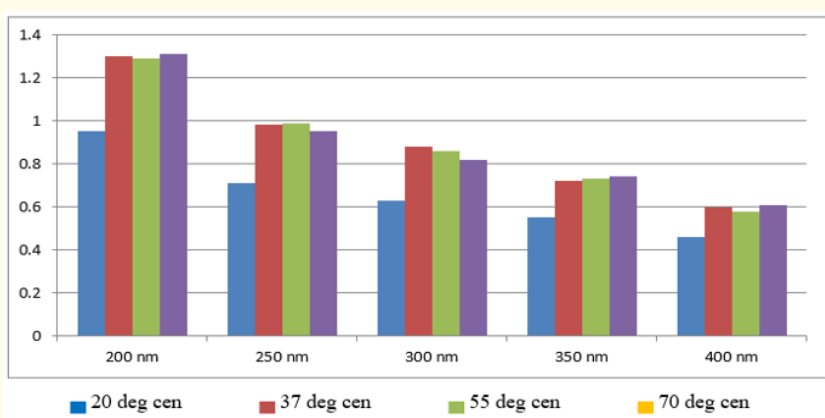

Figure 2: Comparison of anti solar activity of ethanol extract of $A$. conyzoides L. leaves: Effect of temperature. on extraction process.

Effect of time of extraction process on anti solar activity of ethanol extract of $A$. conyzoides L. leaves is shown in figure 3. A. conyzoides L. leaves when extracted with ethanol for $10 \mathrm{~min}, 15$ min, $30 \mathrm{~min}$ and $50 \mathrm{~min}$ separately exert anti solar activity. All extracts absorbed $U V$ rays at $200 \mathrm{~nm}, 250 \mathrm{~nm}, 300 \mathrm{~nm}, 350 \mathrm{~nm}$ and $400 \mathrm{~nm}$ wave lengths. Maximum absorption, however, was found at $200 \mathrm{~nm}$. It was also found that UV ray absorption values of $15 \mathrm{~min}$ ethanol extract of $A$. conyzoides L. leaves was comparatively higher than that of 10 min extraction but the values were not statistically significant. Ethanol extract of A. conyzoides L. leaves done for 30 min and 50 min had more or less same UV ray absorption capacity when compared to that of ethanol extract done for 15 minutes (Figure 4).

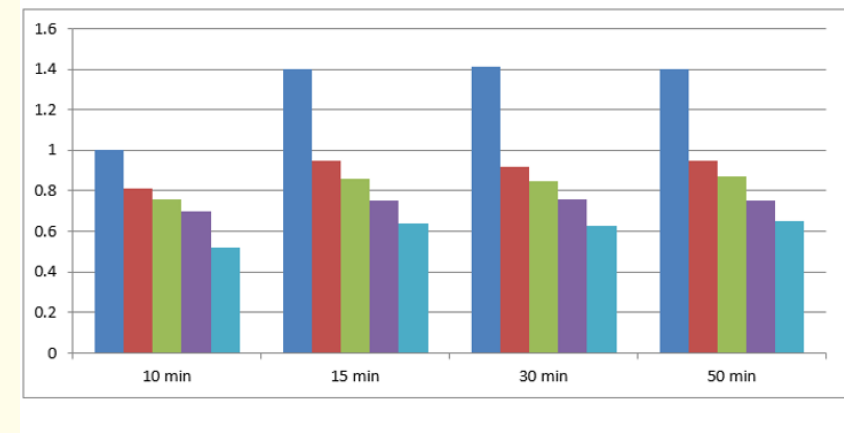

- $200 \mathrm{~nm} \quad 250 \mathrm{~nm} \quad 300 \mathrm{~nm} \quad 350 \mathrm{~nm} \quad 400 \mathrm{~nm}$

Figure 3: Anti solar activity of ethanol extract of A. conyzoides L. leaves : Effect of time of extraction process.

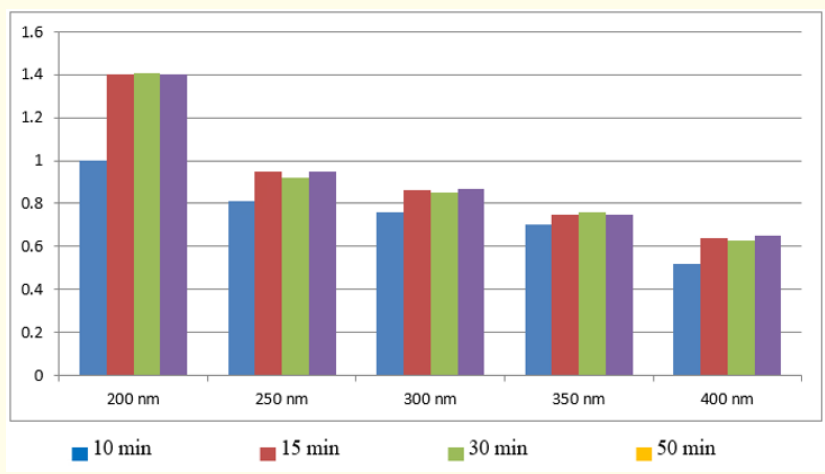

Figure 4: Comparison of anti solar activity of ethanol extract of $A$. conyzoides L. leaves: Effect of time on extraction process. 
Reports are available on effect of time and temperature on extraction process. Terblanche., et al. while conducting screening of variables influencing extraction yield of Cotyledon orbiculata found that the optimum conditions for the aqueous extraction design were extraction temperature $30^{\circ} \mathrm{C}, \mathrm{pH} 8.99$ and extraction time 240 minutes [14]. Hossain., et al. studied effect of temperature and extraction process on antioxidant activity of various leaves crude extracts of Thymus vulgaris and noted that the yield of extraction was increasing with increasing temperature [15]. Jahangiri., et al. while studying effect of temperature and solvent on the total phenolic compounds extraction from leaves of Ficus carica observed that percentage extraction could be increased using a higher temperature of $80^{\circ} \mathrm{C}$ [16]. Norshazila., et al. studied effect of time and temperature on extraction of pumpkin carotenoids and found that optimum time and temperature for the extraction process are 12 hours and $30^{\circ} \mathrm{C}$ respectively [17]. While experimenting on the effect of ethanol concentration, extraction time and extraction temperature on the recovery of phenolic compounds and antioxidant capacity of Centella asiatica extracts Chew., et al. noted that optimal conditions for phenolic recovery were $40 \%$ ethanol for $60 \mathrm{~min}$ at $65^{\circ} \mathrm{C}$ [18]. Mitra., et al. showed that anti solar activity of Costus seciosus leaves of Sikkim Himalayas depends on time and temperature of the extraction process [19]. In the present work we found that ethanol extract of $A$. conyzoides L leaves for a period of $15 \mathrm{~min}$ at temperature $370 \mathrm{C}$ had maximum UV ray absorption capacity.

It is known that biological activity of medicinal plants varies with season [20-22]. We are now interested to see the effect of season on solar UV radiation absorption by $A$. conyzoides L leaves. Work is now going on in our laboratory in this direction.

\section{Conclusion}

Present study confirmed extraction time and temperature for preparation of ethanol extract of $A$. conyzoides $L$ leaves required for maximum UV radiation absorption. The conditions may be applied to get maximum UV radiation absorption by $A$. conyzoides $\mathrm{L}$ leaves.

\section{Recommendation}

Ethanol extract of $A$. conyzoides L. leaves for a period of $15 \mathrm{~min}$ at temperature $37^{\circ} \mathrm{C}$ may be used in preparation of sun screen lotions to protect humans from UV radiation.

\section{Acknowledgement}

We gratefully acknowledge the cooperation of taxonomists of the department of Botany, University of North Bengal, Siliguri, Dist. Darjeeling, West Bengal for identification of $A$. conyzoides L. leaves.

\section{Conflict of Interest}

Nil.

\section{Bibliography}

1. Hamzah., et al. "Effect of extraction time and temperature on the extraction of phenolic compounds from Orthosiphon stamineus leaves". Australian Journal of Basic and Applied Sciences 11.3 (2017): 15-21.
2. Tan., et al. "Effects of extraction solvent system, time and temperature on total phenolic content of henna (Lawsonia inermis) stems". International Food Research Journal 20.6 (2013): 3117-3123.

3. Wingard SK and Phillips RC. "Effect of temperature on the rate of extraction of crude oils from vegetable oil seeds with solvents". Journal of the American Oil Chemists Society 28 (1951): 149-152.

4. Sulaiman., et al. "Effects of temperature, time, and solvent ratio on the extraction of phenolic compounds and the anti-radical activity of Clinacanthus nutans Lindau leaves". Chemistry Central Journal 11 (2017): 54-59.

5. Chaowalit M and Chitradee L . "Effect of Temperature and Duration Time of Maceration on Nitrate Content of Vernonia cinerea (L.) Less.: Circumscribed Central Composite Design and Method Validation". International Journal of Food Science 5.1 (2019) 8-15.

6. Mahmoud., et al. "Effect of time and traditional extraction on antioxidant activity of three Lavandula species". Global Journal of Medicinal Plants Research 4.3 (2016): 6-8.

7. Chopra Col Sir RN and Chopra IC. Indigenous drugs of India, U. N. Dhar and Sons Private Limited, Kolkata (1958): 668.

8. Handa SS and Vasisht K. Compendium of Medicinal and Aromatic Plants-Asia, II, ICS- UNIDO, Area Science Park, Padriciano, Trieste, Italy. (2006): 79-83.

9. Vaidyaratnam Varier PS. Indian Medicinal Plants - A Compendium of 500 species, I, Orient longman publishing house, Kottakkal-India. (2002); 146.

10. Pullaiah T. "Encyclopaedia of world medicinal plants". New Delhi (India): Regency Publications (2006).

11. González AG., et al. "Chromenes from Ageratum conyzoides". Phytochemistry 30 (1991): 1137-1139.

12. Kaur R and Dogra NK. "A Review on Traditional Uses, Chemical Constituents and Pharmacology of Ageratum conyzoides L. (Asteraceae)". International Journal of Pharmaceutical and Biological Archives 5.5 (2014): 33-45.

13. Bliss CI. "Statistics in biology, Statistical methods for research in the natural Sciences". McGraw Hill Book Company, NY 1 (1967): 558.

14. Terblanche., et al. "Screening of Variables Influencing Extraction Yield of Cotyledon orbiculata: Full Factorial Design". International Journal of Pharmacognosy and Phytochemical Research 9.3 (2017): 303-312. 
15. Hossain., et al. "Effect of temperature and extraction process on antioxidant activity of various leaves crude extracts of Thymus vulgaris". Journal of Coastal Life Medicine 1.2 (2013): 130134.

16. Jahangiri., et al. "Effect of temperature and solvent on the total phenolic compounds extraction from leaves of Ficus carica". Journal of Chemical and Pharmaceutical Research 3.5 (2011): 253-259.

17. Norshazila., et al. "The Effect of Time, Temperature and Solid to Solvent Ratio on Pumpkin Carotenoids Extracted Using Food Grade Solvents". Sains Malaysiana 46.2 (2017): 231-237.

18. Chew., et al. "Studied effect of ethanol concentration, extraction time and extraction temperature on the recovery of phenolic compounds and antioxidant capacity of Centella asiatica extracts". Pharmacognosy Journal 9.6 (2017): 767-774.

19. Mitra., et al. "Anti Solar Activity of Costus Speciosus Leaves of Sikkim Himalayas: Effects of Time \& Temperature on Extraction Process". Scholars Academic Journal of Pharmacy 9.1 (2020): 9-13.

20. Schultz JC., et al. "Seasonal and individual variation in leaf quality of two northern hardwoods tree species". American Journal of Botany 69 (1982): 753-759.

21. Arambewela LSR and Ratnayake CK. "Vasicine contents and their seasonal variation in Adhatoda vasica". Fitoterapia 59.2 (1988): 151-153.

22. Ghosh., et al. "Effect of Season on UV Absorption Property of Costus Speciosus Leaves of Sikkim Himalayas". Scholars Academic Journal of Pharmacy 9.1 (2020): 14-17.

\section{Assets from publication with us}

- Prompt Acknowledgement after receiving the article

- Thorough Double blinded peer review

- Rapid Publication

- Issue of Publication Certificate

- High visibility of your Published work

Website: www.actascientific.com/

Submit Article: www.actascientific.com/submission.php Email us: editor@actascientific.com

Contact us: +919182824667 